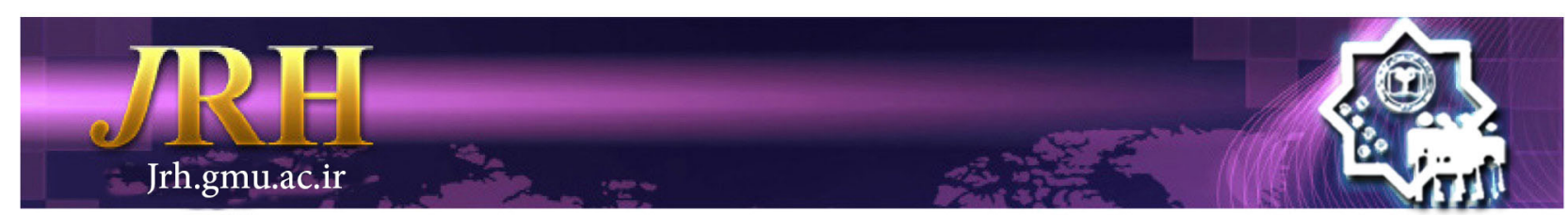

\title{
The effect of transactional analysis group training in psychological hardiness among married women
}

Laya Dindoost ${ }^{1}$, Elaheh Nejadkarim² ${ }^{2}$, Leila Zare Zardini², Hadi Salimi ${ }^{3}$

\author{
Journal of Research \& Health \\ Social Development \& Health Promotion \\ Research Center \\ Vol. 9, No.1, Jan \& Feb 2019 \\ Pages: $37-44$ \\ DOI: $10.29252 / j r h .9 .1 .37$ \\ Original Article
}

1. Department of Counseling, Faculty of Psychology and Educational Sciences, Isfahan University, Isfahan, Iran

2. Department of Counseling, Faculty of Humanities Sciences, Central Tehran Science and Research Branch, Tehran, Iran

3. Department of Counseling, Faculty of Literature and Humanities Sciences, Hormozgan University, Bandar Abbas, Iran

Correspondence to: Leila Zare Zardini, Department of Counseling, Faculty of Humanities Sciences, Central Tehran Science and Research Branch, Tehran, Iran

Email: Lili_a87@yahoo.com

Received: 19 Dec 2015

Accepted: 1 Sep 2018

How to cite this article: Dindoost L, Nejadkarim E, Zare Zardini L, Salimi H. The effect of transactional analysis group training in psychological hardiness of married women. $J$ Research \& Health2019; 9(1): 37- 44.

\begin{abstract}
Psychological hardiness is protective against life difficulties. Hence, it is important to find methods for its improvement. Therefore, this study aimed to evaluate the effect of transactional analysis group training in increasing psychological hardiness among married women. This study was a quasi-experimental researched designed as pretest-posttest with control group. Statistical population consisted of all married women referring to Counseling Center. 30 women were selected through convenience sampling. They were assigned to experimental and control groups. Personal views survey questionnaire was utilized for data collection. The results showed that there were significant differences between control and experimental groups after the intervention; so it can be said that transactional analysis training increased psychological hardiness in the experimental group. According to the findings of this study,According to the findings of this study, transactional analysis can increase psychological hardiness and can be used as an effective clinical intervention by therapists.
\end{abstract}

Keywords: Personality, Psychological Resilience, Transactional Analysis, Women

\section{Introduction}

Up to early 1980 s, many researchers in the area of psychological sciences had believed that stressful events had the primary role in unfolding psychological problems. Yet, subsequent research showed that there are mediating factors between stressful events and psychological disorders that cause stressful events to leave different effects on people. One of the mediating factors is psychological hardiness [1]. Psychological hardiness first introduced by Kubasa, Modi \& Zola emphasizes human's innate experience and mental perception [2]. This concept means patience, resistance, and tolerance in difficulties and hard situations [3] and, in fact, refers to person's performance according to cognitive evaluation [4]. This concept is composed of three components of commitment, control, and challenge [5]. A person with high commitment (opposite to alienation) has perceived his/her value and the meaning of who he/she is and what he/she does. People who are strong in the component of control (opposite to powerlessness) recognize life events as predictable and controllable ones and believe that they are able, by effort, to influence what happens around them. Challenge (opposite to threat or fear) refers to the belief that change, rather than inactivity and stability, is a natural aspect of life [6]. 
Psychological hardiness as a shield against stress in various situations [7] has shown to be effective in maintaining mental health even in a person with a painful life like suffering from AIDS [8]. Based on their investigations, some researchers have stated that it is more likely that childhood experiences and interaction with parents and people around us may lead to a hard personality $[9,10]$. In a research, the components of psychological hardiness were trained to adults and it was found that training can increase the components of psychological hardiness and, subsequently, improve life quality [11]. In researches, it was reported that psychological hardiness has a significant relationship with variables like welfare and mental health [12,13], job burnout [1], life quality and performance improvement [14], family flexibility [15], and hopefulness [16]. Among training and therapeutic procedures used for improving psychological moods of people, transactional analysis (TA) theory is used to treat and improve various mental disorders, from daily problems to deep psychodynamics. Transactional analysis causes people to pay more attention to their feeling, thoughts and other psychological moods and exploit their emotional and mental abilities to overcome problems [17]. Transactional analysis theory was expanded by Eric Berne and it has had significant effects on the improvement of human relationship and, subsequently, better compatibility with others, and finding the way to know oneself [18]. In this theory, concepts like pattern of ego states (parent, adult, and child), transaction, caress, life script, mental plays, autonomy, and self-governing are used [19]. As an interaction therapy procedure, transactional analysis aims at increasing people's knowledge and ability to make new decisions and take personal responsibilities whereby they could change their life mode [20]. These cases become apparent in therapeutic relationship based on contract and therapeutic focus on freedom [autonomy] and empirical challenges on here and now [21]. Berne has categorized therapy into 4 various levels [22]; Social control: The first step in the improvement of clients is controlling unhealthy behaviors in social context, even if they has still bad feelings toward their problems [23]; Symptoms improvement: It is not only related to controlling person's behaviors, but it is accompanied by feeling of getting rid of confusion and anxiety [24]; Transference therapy: In this step, clients are protected by their therapist and see him/ her as a supportive parent beside themselves and, through relying on this transition, they can get rid of script they have written on their evolution path [25]. Script therapy: At the end of therapy, clients attain an integrated "adult" and can help their internal therapist overcome transitional therapy [26]. Transactional analysis is applicable in all professional areas [27]. Results from examining the effect of transactional analysis training on psychological welfare showed that transactional analysis training had a positive effect on psychological welfare and this effect remained stable in the follow-up step [28]. Also, training on it helps increase the ability to tolerate stressful situation and effectively cope with this situation [29]. In another research, researchers reported that, in comparison to cognitive-behavioral therapy, transactional analysis therapy could have more significant stable changes toward improvement of symptoms of emotional breakdown in most therapeutic targets [30]. Although in a research, a significant effect was not observed on transactional analysis group training on the dimensions of self-efficacy among school counselors [31], transactional analysis had a significant effect on many variables like reduced aggressive behavior [32], improvement of relationships [33,34], self-knowledge [35], family performance $[18,36]$, happiness [19], personality moods and self-esteem [22].

According to above materials and the relationship between psychological hardiness and other variables, it is important to pay attention to this psychological variable as a shield against life's stress and problems [7]. Also, transactional analysis has been 
introduced as a useful effective procedure for personal growth, and self-consciousness- in life and interactions among people [36]. So, with regard to the significance of psychological hardiness and effort to find ways to improve it, effect of transactional analysis in various psychological areas and, subsequently, with regard to few and direct researches about effect of transactional analysis, the current research aims at examining the effect of transactional analysis training on the increase of psychological hardiness.

\section{Method}

This quasi-experimental research was designed as pretest/posttest with control group. Statistical population comprised all married women referring to the counseling center in Tehran who received counseling and psychological services in 2015. 30 participants among applicants were selected according to inclusion criteria through convenience sampling. They were randomly assigned to experimental and control groups. participants in the experimental group received transactional analysis in 12 sessions of 3 hours during a 3-month period while the control group received no trainings. The inclusion criteria included gaining low scores on psychological hardiness scale (PVSQ) in pretest, being a married female, being committed to attend all sessions, not using other psychotherapy and counseling services during training sessions, not having psychological problems (paranoid, epilepsy and every psychological problem because of which person was under psychiatrist or using psychiatric drugs), and not addicted to drugs and alcohol. After completing the training period, both groups were again evaluated by the research instrument to be examined for the status of psychological hardiness. To collect data, following instruments were used:

Personal Views Survey Questionnaire: This questionnaire is a self-report scale introduced by Kubasa, Medi \& Bartone that is used to evaluate people's psychological hardiness. This tool has 50 items and includes 3 subscales of control, commitment, and challenge
[37]. Subject should express his/her idea on a 4-point Likert scale rated between 3 and 0 (not true at all, somewhat true, mostly true, and completely true). Personal views scale generates 4 scores: One for the whole scale with 50 items and the other 3 ones for the subscales of commitment with 16 items, control with 17 items, and challenge with 17 items. Researches show that triple components of commitment, control, and challenge have alpha coefficients of $0.70,0.52$, and 0.52 , respectively. This coefficient for the whole scale has reported as 0.75 [38]. In the internal researches, validity and reliability of scale was approved. Its reliability was confirmed by Cronbach's alpha values for the whole scale and sub-scales of commitment, control and challenge as $0.88,0.64,0.72$, and 0.70 , respectively [10]. In another research, Cronbach's alpha coefficient for the whole scale was reported as 0.87 [12].

Data were analyzed in two descriptive and inferential levels. To test research hypotheses, univariate covariance analysis statistical method was used. Data were analyzed using SPSS-22 (level of $p<0.05$ ). It is notable that training package was set according to the researches of Fathipoor et al. [18], Akbari et al. [30], and Javadi et al. [36] and also external literature $[20,39]$ and the comments of academic professors. The educational content is summarized in the Table 1.

\section{Results}

The overall mean age and marriage durability of subjects were 43.29 and 22.79 with standard deviation of 6.34 and 8.81, respectively. They were 43.05 and 23.44 with standard deviation of 6.98 and 9.54 in the experimental group and 43.53 and 22.13 with standard deviation of 5.86 and 8.27 in the control group.

Descriptive examination of data shows that mean and standard deviation of pretest scores of total scale psychological hardiness were respectively 97.8 and 16.75 in the experimental group and 102.6 and 13.79 in the control group. In the posttest, however, the mean score in the experimental group increased to 108.4 and in 
Table 1 A summary of transactional analysis training sessions

\begin{tabular}{|c|c|}
\hline Sessions & Contents \\
\hline Session 1 & $\begin{array}{l}\text { Setting communication with members, administrating pretest, asking expectations of members from the } \\
\text { class, introducing transactional analysis, personality imaging, introducing ego state pattern, examples of } \\
\text { shift in ego state }\end{array}$ \\
\hline Session 2 & $\begin{array}{l}\text { Analysis of ego state action, training to draw ego state diagram, training to recognize ego state, behavioral } \\
\text { recognition, social behaviors recognition }\end{array}$ \\
\hline Session 3 & $\begin{array}{l}\text { Training various types of transaction, complementary transaction, crossed transaction, ulterior transaction, } \\
\text { hidden messages, engaging in exercise in the class (playing a role of each of relationship) }\end{array}$ \\
\hline Session 4 & Training caress, types of caress, self-caress, caress economy, homework assignment \\
\hline Session 5 & $\begin{array}{l}\text { Reviewing homework of previous session, training how to organize the time, isolation, ceremony and } \\
\text { rituals, temporization, activities and mental plays, homework assignment }\end{array}$ \\
\hline Session 6 & $\begin{array}{l}\text { Reviewing homework of previous session, introducing life script, doing exercises in the class and training } \\
\text { life situation, homework assignment }\end{array}$ \\
\hline Session 7 & $\begin{array}{l}\text { Reviewing homework of previous session, training deterrents and explaining the deterrent: don't exist- be } \\
\text { yourself, doing exercises, homework assignment }\end{array}$ \\
\hline Session 8 & $\begin{array}{l}\text { Reviewing homework of previous session, explaining the deterrents: don't be kid- don't be adult- don't } \\
\text { be successful- don't be absolute- don't be intimate- be ill- don't think- don't feel, doing exercises and } \\
\text { homework assignment }\end{array}$ \\
\hline Session 9 & $\begin{array}{l}\text { Reviewing homework of previous session, introducing and explaining impellents: be complete- be happy } \\
\text { and try hard- be strong and hurry up, doing exercises and homework assignment }\end{array}$ \\
\hline Session 10 & $\begin{array}{l}\text { Reviewing homework of previous session, introducing mental plays, examples from mental plays, doing } \\
\text { exercises and homework assignment }\end{array}$ \\
\hline Session 11 & $\begin{array}{l}\text { Reviewing homework of previous session, training plays' characteristics, ranking mental plays, } \\
\text { introducing dramatic triangle of Stephen-Kariman, giving examples of roles of dramatic triangle, doing } \\
\text { exercises and homework assignment }\end{array}$ \\
\hline Session 12 & $\begin{array}{l}\text { Reviewing homework of previous session, explaining the reasons to do mental plays by people (plays, } \\
\text { stamps, outcome, script), reinforcing life script, the way to behave with plays, administrating posttest }\end{array}$ \\
\hline
\end{tabular}

Table 2 Descriptive findings of psychological hardiness in the experimental and control groups

\begin{tabular}{llcccccc}
\hline \multirow{2}{*}{ Number } & \multicolumn{3}{c}{ Experimental Group } & \multicolumn{3}{c}{ Control Group } \\
\cline { 3 - 8 } & & $\mathrm{M}$ & $\mathrm{SD}$ & $\mathrm{N}$ & $\mathrm{M}$ & $\mathrm{SD}$ & \\
\hline $\begin{array}{l}\text { Psychological } \\
\text { hardiness }\end{array}$ & Pretest & 15 & 97.8 & 16.75 & 15 & 102.6 & 13.79 \\
& Posttest & 15 & 108.4 & 13.42 & 15 & 99.4 & 14.88 \\
\hline
\end{tabular}

the control group it decreased to 99.43. covariance analysis method was used. For To examine research questions, univariate this purpose, at first, covariance analysis

Table 3 Findings of Shapiro-Wilk test to examine normality of psychological hardiness scores

\begin{tabular}{lccc}
\hline Test Stage & Shapiro-Wilk & df & $\mathrm{p}$ \\
\hline Pretest & 0.958 & 30 & 0.272 \\
Posttest & 0.972 & 77030 & 0.583 \\
\hline
\end{tabular}

presuppositions are examined.

To examine normality of psychological hardiness scores, Shapiro-Wilk test was used. As seen in Table 3, since values of Shapiro-
Wilk test for psychological hardiness variable is not significant in any steps of pretest and posttest in the experimental group ( $\mathrm{p}>0.05)$, it is concluded that scores distribution in this

Table 4 Findings of Levene's test about homogeneity of variances

\begin{tabular}{lcccc}
\hline Test state & $\mathrm{F}$ & $\mathrm{df1}$ & $\mathrm{df} 2$ & $\mathrm{p}$ \\
\hline Pretest & 0.685 & 1 & 28 & 0.415 \\
Posttest & 0.006 & 1 & 28 & 0.938 \\
\hline
\end{tabular}


variable is normal.

To examine presupposition of variances homogeneity, Levene's test was used. As see in Table 5, F statistics value for psychological hardiness variable is not significant in the posttest ( $\mathrm{p}>0.05)$; Hence, presupposition about variances equality in two experimental and control groups in psychological hardiness

Table 5 Findings of covariance analysis about experiment effect on psychological hardiness

\begin{tabular}{lccccc}
\hline Variable & SS & df & MS & F & p \\
\hline Pretest effect & 3435.017 & 1 & 3435.017 & 42.34 & 0.001 \\
Posttest effect & 1159.701 & 1 & 1159.701 & 14.29 & 0.001 \\
Error & 2190.183 & 27 & 81.118 & & \\
Total & 330089 & 30 & & & \\
\hline
\end{tabular}

variable is approved.

Table 4 shows a significant difference between two experimental and control groups in terms of psychological hardiness. With regard to $\mathrm{F}$ values (14.29) and its significance level which is lower than 0.05 , it is observed that transactional analysis training was effective in the increasing psychological hardiness in the experimental group; hence, research hypothesis is confirmed.

\section{Discussion}

The current research aimed at examining the effect of transactional analysis on psychological hardiness. The results of statistical data analysis showed that there was a significant difference between experimental group and control group in terms of posttest scores of psychological hardiness; hence, transactional analysis training caused psychological hardiness to increase. In the case of examining the effect of transactional analysis training on psychological hardiness, it was not found a research to be directly examined. However, some researches on variables close to psychological hardiness have approved the effect of transactional analysis [29,40]. The results of researches examining the effect of transactional analysis in addicts who were detoxified or in the process of rehabilitation showed that transactional analysis training would cause an increase in control and a decrease in temptation and relapse [40]. In another research, the result demonstrated that transactional analysis training would increase the ability to tolerate stressful situation and effectively cope with it [29]. In other areas, researches on the effect of transactional analysis training showed that the training would promote family performance $[18,36]$, improve relationships [32,34], and decrease aggressiveness [32].

Psychological hardiness, i.e. patience, resistance, and tolerance in difficulties and hard situations [3], in fact, refers to person's performance based on cognitive evaluation [4] and it is composed of three components of commitment, control, and challenge [5] and works as protecting factor against problems [7]. Hence, finding a way to increase psychological hardiness is important. Transactional analysis is applicable in all professional areas [27] with the aim of increasing people's knowledge and power to make new decisions and take new responsibilities [21]. It is also used to treat various mental disorders, from daily problems to deep psychodynamics [18]. In a research, it was shown that exploiting transactional analysis caused psychological welfare to increase and in another research, it caused hopefulness to increase [19]. In the other one, transactional analysis therapy caused an improvement in symptoms of emotional breakdown [22,30]. To explain these findings, one can say that transactional analysis caused an increase in patience, resistance, and tolerance in people with emotional breakdown. In other words, it led them to psychological hardiness. Transactional analysis training accompanied by the increased ability for communication skills, leaving destructive scripts, taking responsibilities, improving problem-solving skills, emotional skills and, at the same time, increased individuation and fulfilling other self and choosing healthy existence situation for life during an interpersonal-intrapersonal 
process correction [22] could lead to improving people's ability to tolerate hard situation. In another perspective, people, by having knowledge on their own personality dimensions [child, parent, and adult] can, while confronting various problems and situations, behave in such a way suitable for their personality and it causes they behave more compatible and acceptable in situations ahead.

Also, one dimension of psychological hardiness is the control component (opposite to powerlessness). People with high control level see life events as controllable and predictable ones and believe that they can, by effort, influence what happens around them [6]. In this case, by being subject to transactional analysis training, all three personality states of the person could change and grow [22]. Adult, which its task is to analyze data and make prediction, by being subject to training, works better and more accurate and becomes more reasonable and realistic [36]. This leads to the fact that one with activated adult predicts his/ her life events more accurately and, by preciously analyzing phenomenon and problems, controls them in a better manner.

Among other components of psychological hardiness is commitment (opposite to alienation). People with high commitment have perceived the significance of his/her value and the meaning of who they are and what they do [6]. In this dimension, transactional analysis training causes people's self-consciousness to increase toward being more responsible for their behaviors [29]. Researches in this area have approved the effect of transactional analysis training in increasing self-consciousness [29, 35]. These trainings cause subjects to know themselves as valuable and once they achieve a success, they would encourage themselves more and more and tolerate faults and consider them as an opportunity to learn; hence, they criticize themselves less [29]. Transactional analysis teachings in the area of revising prejudices, unreasonable dos and don'ts and irritating sentences evident in parent and, also, controlling impulsivity and feeling of not being ok in "child" by parent reinforcement can lead to cognitive reconstruction and healthy situation of "I am ok, you are ok" [32].

The other component of psychological hardiness is challenge (opposite to threat or fear). People with high challenge levels know that change, rather than inactivity and stability, is a natural aspect of life [6]. Transactional analysis educates deeply clients how to make decisions, it says to them that, by making this decision, what will happen for them and the fact that, in the future, how they revise their scripts. Also, by training deterrent and driving factors, a trainee would know factors which cause stasis and factors which cause change and movement; hence, the person, by knowing these factors, becomes able to avoid stability and move ahead.

Due to some limitations like time limitation meaning lack of follow-up possibility and using questionnaire as the only instrument for assessing psychological hardiness, caution should be done for generalizing data and results. It is suggested that counselors and psychologists use transactional analysis training in health care area and also researchers begin to investigate the effect of transactional analysis training in various psychological constructs.

\section{Conclusion}

With regard to the research findings, we can conclude that transactional analysis training, by following its objectives based on increasing knowledge, making decision, and taking responsibilities, causes people to increase their compatibility and cognitive capacities and, while confronting various problems, they can tolerate difficulties and be compatible with problems. In other words, transactional analysis makes people commit to life, consider life as a predictable matter and can control it, and also make changes and challenges for achieve to better conditions. transactional analysis is a useful method for self-consciousness and helps people with their job and life.

\section{Acknowledgements}

Authors would like to appreciate all research 
participants and friends who have helped us with this research.

\section{Contribution}

Research design: DL, ZZL, NA.

Data collection and analysis: SH, ZZL.

Article preparation: SH, NA.

\section{Conflict of Interest}

"The authors declare that they have no competing interests."

\section{Financial}

The author (s) received no financial support forthe research, authorship and/or publication of this article.

\section{References}

1- Shakeriniya I. The relationship between ethical conflicts, moral distress, and occupational stress in nurses. Iranian Journal of Medical Ethics and History of Medicine2011; 4(1):56-69.

2- Kobasa SC, Maddi SR, Zola MA. Type A and hardiness. J Behav Med1983; 6(1): 41-51.

3- Jafari E, Sohrabi F, Jomehri F, Najafi M. The relation ship between type $\mathrm{C}$ personality, locus of control and hardiness in patients suffering from cancer and normal subjects. Journal of Clinical Psychology2009; 1(1): 57-66. 4- Woodard CR. Hardiness and the concept of courage. Consulting Psychology Journal: Practice and Research2004; 56(3): 173-85.

5- Maddi SR. Hardiness: an operationalization of existential courage. J Humanist Psychol2004; 44(3): 279-98.

6- Mostaghni S, Sarvghad S. Relationship of Personality Characteristics and Psychological Hardiness with Job Stress of Nurses of Public Sector Hospitals in Shiraz. Knowledge \& Research in Applied Psychology2013; 13(4): 124-32.

7- Beasley M, Thompson T, Davidson, J. Resilience in responses to life stress: the effects of coping style and cognitive hardiness. Personality and Individual Differences2003; 34(1): 77-95.

8- Vance DE, Struzick TC, Masten J. Hardiness, successful aging and HIV: Implications for social work. $J$ Gerontol Soc Work2008; 51(3/4) 260-83.

9- Kobasa SC, Puccetti MC. Personality and social resources in stress resistance. J Pers Soc Psychol1983; 45(4): 839-50.

10- Talebzadeh Nobarian M, Seidi MS, Mousavi SH, Mirlou MM. Parenting spirituality, quality of family communication, and students' psychological hardiness: the mediating role of family communication. Journal of
Family and Research2013; 10(3): 7-21.

11- Shokoohi Fard S, Hamid N, Sodani M. The effect of hardiness training on quality of life of teachers training female students. Knowledge \& Research in Applied Psychology2013; 14(2): 14-25.

12- Shakarami M, Davarniya R, Zahrakar K, Hosseini A. The predictive role of psychological capital, psychological hardiness and spiritual intelligence in students' psychological wellbeing. $J$ Research Health2014; 4(4): 935-943.

13- Bakhshi Arjenaki B, Sharifi T, Ghasemi Pirbalouti M. Assessment the relationship of psychological well-being with religiosity attitude, self-esteem and psychological hardiness by equation structural modeling among students of Islamic Azad and public universities in Shahrekord. Journal of Health Promotion Management2015; 4(3): 60-9.

14- Aubi S, Teimory S, Nayyeri M. Hardiness, quality of life and well-being. Developmental Psychology: Journal of Iranian Psychologists2010; 6(24): 353-60.

15- Bahadori E, Khayyer M, Samani S. The relationship between psychological hardiness with family flexibility and coping styles with stress. Journal of Psychological Methods and Models2012; 2(7): 1-18.

16- Zahed Babelan A, GhasempourA, Hasanzade Sh. The role of forgiveness and psychological hardiness in prediction of hope. Knowledge \& Research in Applied Psychology2011; 12(45): 12-19.

17- Fathipouri M, Ebrahimi Nejad G, Khosravi S, Rezaeian M, Pourshanazari A. The effect of transactional analysis training on improving the parent's functions of high school boy students in Rafsanjan. Journal of Rafsanjan University of Medical Sciences2010; 9(1):47-58.

18- Allameh SF, Aghaei A, Atashpour SH, Moshtaghi M. The effect of transactional analysis group training on married men's happiness referred to counseling and cultural centers. Research in Cognitive and Behavioral Sciences2014; 4(1): 25-38.

19- Stewart L, Joines V. TA Today: A new introduction to transactional analysis. 7th ed. Carolina: Lifespace; 2007. 20- Corey G. Theory and practice in group counseling and therapy. 4th ed. Boston, Massachusetts, US: Brooks Cole; 1995.

21- Akbari A, Khanjani Z, Azimi Z, Pour Sharifi H, Mahmoud Alilou M. The effectiveness of transactional analysis therapy on personality states, self-esteem and clinical symptoms of people with emotional breakdown. Journal of Psychological Methods and Models2012; 2(8): 1-20.

22- Mousavi AS. Permarital counseling: with an applied look. Tehran: Mehr Kavian; 2007.

23- Berk LE. Development Through the Lifespan. Translated by Seyedmohammadi Y. Tehran: Arasbaran; 2008. 
24- Poursharifi H, Peyravi H, Taremyan F, Zarani F, Vaghar M, Jafari AA. The investigation of mental health among new entrance students in the academic year 2004 at the universities covered by the Ministry of Science, Research and Technology. Third seminar of students mental health; 2005 March 2-3; Tarbiat Modares University, Tehran, Iran; 2005.

25- Rosse RB. The love trauma syndrome: free yourself from the pain of a broken heart. US: Da capo lifelong books; 1999.

26- Johnsson R. Transactional analysis psychotherapy: three methods describing a transactional analysis group therapy [dissertation]. Department of psychology. Lund, Sweden: Lund university 2011. pp: 5-75.

27- Schimid B. The role concept of transactional analysis and other approaches to personality, encounter and creativity for all professional fields. Transactional Analysis Journal2008; 38(1): 17-30.

28- Sodani M, Momeni Javid M, Mohammadi K. The impact of training in transactional analysis on psychological well-being and self-knowledge of married women. Biannual Journal of Applied Counseling2013; 3(2): 51-64.

29- Farhangi F, Agha Mohammadian Sherbaf HR. The study of impact of group psychotherapy on stress coping styles in adolescences based on transactional analysis approach. Studies in Educational \& Psychology2006; 7(2): 41-62.

30-Akbari E, Khanjani Z, Poursharifi H, Mahmoud-Alilou $\mathrm{M}$, Azimi Z. Comparative efficacy of transactional analysis versus cognitive behavioral therapy for pathological symptoms of emotional breakdown in students. Journal of Clinical Psychology2012; 4(3):87-101.

31- Keramati R, ShoaKazemi M, Tanhaye Reshvanloo F, Hosseinian S. The effectiveness of group training for reciprocal behavior analysis on the self-efficacy among school counselors. Journal of Research and Health2015; 5(1): 104-12.

32- Kazemi Z, Neshatdoust HT, Kajbaf MB, Abedi A,
Agha Mohammadi S. The effect of transa cional analysis training on the reduction of aggressive behavior of 3 runway girls in Isfahan: a single-subject design research. Woman and Study of Family2011; 3(10): 111-29.

33- Kazemi Z, Neshatdoust HT, Kajbaf MB, Abedi A, Aghamohammadi S, Sadeghi S. The effect of transactional analysis training on runaway girls' social intimacy in Isfahan a single-subject design research. Quarterly Womens Studies2012; 10(3): 139-61.

34- Sadeghi M, Ahmadi SA, Bahrami F, Etemadi O, Pourseyed SR. The effect of transactional analysis training on love styles of couples. Journal of Researches of Cognitive and Behavioral Sciences2014; 3(2): 71-84. 35- Fotoohi Bonab S, Hosseininasab SD, Hashemi T. Effectiveness of cognitive-Behavioral, Islamic and Transactional Analysis couple therapy on Self - Knowledge of incompatible couples. Journal of Psychological Studies2011; 7(2): 37-58.

36- Javadi B, Hosseinian S, Shafiabadi A. The effectiveness of transactional analysis training on mothers to improve their family function. Journal of Family Research2009; 5(4): 503-17.

37- Bartone PT, Hystad SW, Eid J, Brevik JI. Psychological hardiness and coping style as risk/ resilience factors for alcohol abuse. Mil Med2012; 177(5): 517-24.

38- Bayrami M, Zahmatyar H, Khosroshahi J. Prediction strategies to coping with stress in the pregnancy women with first experience on the based factors hardiness and social support. Iranian Journal of Nursing Research2012; 7(27): 1-9.

39- Stewart I. Transactional Analysis Counselling in Action. Translated by Atarha N. Tehran: Fara Ravan publication; 2013.

40- Monajem A, Aghayousefi A. Effectiveness of group psychotherapy of transactional analysis in craving beliefs, attachment styles and cognitive emotion regulation in addicts under treatment. Journal of Research on Addiction2015; 9(34): 123-144. 